\title{
Perceptual motor dysfunction in Parkinson's disease: a deficit in sequential and predictive voluntary
} movement

\author{
YAAKOV STERN,${ }^{*} \dagger$ RICHARD MAYEUX, $\dagger$ JEFFREY ROSEN,${ }^{*}$ JOYCE ILSON $\dagger$ \\ From the Departments of Psychology, City University of New York* and Neurology, Columbia University \\ College of Physicians and Surgeons, $†$ New York, USA
}

SUMMARY We studied the ability of Parkinsonian patients and controls to generate voluntary movements on a tracing task. Subjects were videotaped while tracing designs of increasing complexity, presented on a vertical, transparent screen. Some designs were presented in a degraded form and subjects filled in their missing sections. Subjects also received a constructional task and a test of general intellectual ability. The quality of errors on the tracing task differed in the Parkinsonian and control groups. Parkinsonian patients made two distinct types of errors. One probably related to the motor disorders of the disease, but another seemed to be related to a higher level of control over sequential and predictive movements. The latter correlated with performance on the constructional and general intellectual tasks. These results suggest that Parkinson's disease may affect basal ganglia structures that are necessary for voluntary movements which require sequencing or planning. Clinically this may be observed in perceptual motor tasks since they require both voluntary movement and sequential organisation of behaviour.

Impairments in perceptual motor or visuospatial tasks are among the most frequently encountered abnormalities in neuropsychological studies of Parkinson's disease..$^{1-5}$ Many of these tasks require voluntary movements, so these deficits could reflect nothing more than the disordered movement of Parkinson's disease. Alternatively, this disturbance in perceptual motor tasks suggests that there may also be a loss of higher order motor control that is distinct from the characteristic motor disorders of Parkinson's disease. Certain deficits on tracking tasks in Parkinson's disease can be characterised as an inability to generate and sequence predictive movements, that is movements that must be accomplished without external feedback to guide them. For example, Flowers ${ }^{6}$ demonstrated that while Parkinsonian patients could successfully track a target moving on an oscilloscope screen in a regular pattern at a sufficiently slow speed, tracking performance degenerated when the target was momentarily removed from the screen. This perceptual motor deficit

Address for reprint requests: Dr Mayeux, The Neurological
Institute, 710 West 168th Street, New York, New York 10032, USA.

Received 8 April 1982 and in revised form 27 September 1982 Accepted 4 October 1982 may be a result of impaired generation of control of sequential and predictive voluntary movements.

To examine this hypothesis, we tested patients with a simplified version of Flowers' tracking task, ${ }^{6}$ and with a constructional task. In addition, general intellectual function and the severity of symptoms were assessed. We expected that certain errors in tracing would relate to the severity of patients' Parkinsonism, that is tremor, rigidity or bradykinesia. However, we anticipated that other errors in tracing, particularly those demanding predictive movement, might be related to performance on the constructional and general intelligence tests and not to the severity of the Parkinsonism. This work was presented in part at the 33rd annual meeting of the American Academy of Neurology. ${ }^{7}$

\section{Methods}

\section{Subjects}

Eighteen patients with Parkinson's disease and 14 healthy, elderly adult controls volunteered and gave informed consent. We excluded people with a history or overt signs of dementia as defined by the DSM III. ${ }^{8}$ Fourteen of the 18 patients were on levodopa therapy (table 1). All subjects were examined by the same neurologist. For the patients, we used a standardised evaluation form rating 21 signs and 
Table 1 Subjects: descriptive information. Values in parentheses are standard deviations

\begin{tabular}{|c|c|c|}
\hline & Parkinson's disease & Control \\
\hline $\begin{array}{l}\text { N } \\
\text { Age } \\
\text { Education (years) } \\
\text { Mini-Mental State } \\
\text { Parkinson's disease } \\
\text { evaluation } \\
\quad \text { Total } \\
\quad \text { Tremor } \\
\text { Bradykinesia } \\
\text { Rigidity } \\
\text { Duration of illness } \\
\text { N on levodopa (Sinemet) } \\
\text { Levodopa dosage }\end{array}$ & $\begin{array}{c}28.8(12.8) \\
1.8(2.4) \\
1.5(0.9) \\
4.6(2.7) \\
9.6(8.2) \\
14 \\
1.4 \mathrm{gms} / \text { day }\end{array}$ & $\begin{array}{r}14 \\
72 \cdot 0(3 \cdot 8) \\
9 \cdot 7(2 \cdot 6) \\
50 \cdot 3(4 \cdot 6)\end{array}$ \\
\hline
\end{tabular}

symptoms of Parkinson's disease from $0-4$ ( 0 indicating the absence and 4 indicating the highest severity); higher total Parkinson's disease evaluation scores indicated higher Parkinson's disease severity. Rigidity and tremor ratings were the sum of ratings of each of the four limbs and the neck or head. Controls were examined to ensure the absence of any neurological disorder.

\section{Neuropsychological testing}

We used a brief but thorough measure of intellectual function, a modified version of Mini-Mental State examination (MMS). ${ }^{9}$ Previously, we have found this measure to be a useful indication of intellectual function in Parkinson's disease. ${ }^{5}$ The maximum possible score on the modified MMS is 57. In addition, all subjects completed the Rosen Drawing Test ${ }^{10}$ the subject copied 15 designs ranging in complexity from those testing simple concepts of topological space to 3-dimensional figures.

\section{Tracing task}

Paths drawn in black ink (approximately $6 \mathrm{~mm}$ thick) on clear plastic sheets were affixed to a $60 \times 60 \mathrm{~cm}$ plexiglass screen mounted perpendicular to a table (fig 1). Basic paths consisted of a straight line in horizontal and vertical orientation and a saw-tooth pattern. Further paths were constructed by deleting segments of the original ones; two endpoints represented the straight line and the sawtooth pattern was modified by the removal of a straight line segment, or one or two angular segments. Subjects traced the mounted paths with their index finger and a felt pad reduced friction between the finger and plexiglass. Tracing performance was recorded using a video camera mounted on the other side of the plexiglass screen. Subjects sat at the edge of a table within comfortable reach of the tracing screen. Paths were administered in the sequence shown in fig 1 . Subjects were instructed to trace each path with their index finger, moving at their own pace. At the end of each path they turned and continued tracing for a total of three times back and forth. Subjects were cautioned to stay on the path. Left hand performance followed right. For the partially deleted paths (Paths 3, and 5-7), there were additional instructions. For Path 3, subjects were instructed to move between the endpoints in a straight line. Before tracing Paths 5, 6 and 7, Path 4 was superimposed to demonstrate that the current path was similar but that a
1

2

\section{3}

\section{Fig 1 Paths used in tracing task.}

segment had been deleted. Subjects were permitted to compare the two paths until they were satisfied that they could perceive the shape of the missing segment. They then traced the partially deleted path, filling in the missing segment. Path 4 was removed during tracing. When severe errors occurred on Path 7 (according to the criteria described below), Path 4 was redisplayed, subjects were permitted to study the missing segment and trace it with their finger, and Path 7 was then readministered.

Rating. Videotaped tracing performance was rated by two neurologists who did not know the results of neuropsychological testing. In pilot work, we identified four types of errors in Parkinson's disease patient tracing performance. These errors were rated from 0 to 2 with 0 indicating absence of error, 1 , slight error and 2, severe error: (1) loss-of-form: distortion of missing segments. Displacement of the relative position of portions of the pattern or the rounding of angles was related as a slight error (rating = 1). Grosser distortions were rated as severe (rating = 2) (see fig 2). (2) tracing error: slight (rating = 1) or severe (rating $=2$ ) deviation from the displayed portions a

4

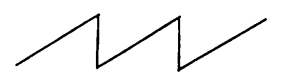

5

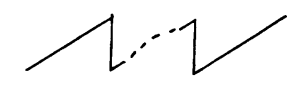

6

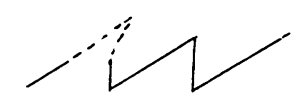

7

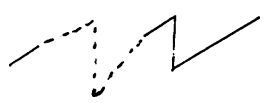

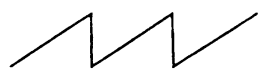
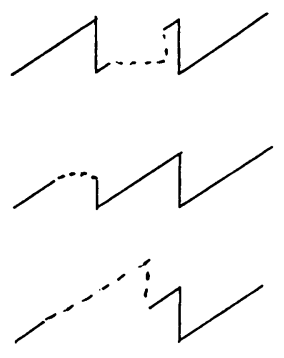

Fig 2 Selected examples of slight (a) and severe (b) loss-ofform errors on paths 5-7. Path 4 is included for comparison. 
of the path. (3) tracing hesitation: a one (rating = 1) or two (rating $=2$ ) second hesitation during tracing but not at an end point. (4) endpoint hesitation: hesitation at endpoints scored as in tracing hesitation. Before rating subjects' performance, the raters reviewed tapes to establish concordance on rating criteria. During rating, any disagreement was settled by reviewing taped performance until concensus was reached. Tracing and hesitation errors were scored each time they occurred and were summed for each cycle of movement from the starting point of a path back to the starting point. Loss of form errors could occur only twice in each cycle.

\section{Results}

Parkinsonian patients were comparable in age, intellectual evaluation scores, and disease severity to those we have studied previously (table 1 ). ${ }^{5}$ Controls were significantly older and less educated than our Parkinsonian patients $(\mathrm{p}=0.05$; table 1$)$. For control and Parkinson's disease groups respectively, mean MMS scores were 50.2 (SD = 4.6) and 51.2 $(\mathrm{SD}=$ 6.6) and Rosen Drawing test scores were 10.3 (SD = $2 \cdot 2)$ and $10 \cdot 9(\mathrm{SD}=2 \cdot 7)$. No significant difference existed between groups on these measures.

No difference was found between performance on successive tracing cycles of a particular path or between left and right hand. Therefore ratings for each type of error were summed across these dimensions for each path.

Loss-of-form-errors. The frequency and severity of loss-of-form errors, as well as the qualitative characteristics of errors differed in the Parkinson's disease and control groups. In the Parkinson's disease group, loss-of-form errors occurred in all paths with increased frequency and severity of errors in Paths 6 and 7 (table 2). Patients often made errors consisting of the displacement of the relative position of missing segments or distortion and rounding off of angles (see fig 2). In Path 7, only one of the patients expressed an awareness of making an error and only one of the four patients who made severe errors on

Table 2 Loss-of-form errors. Number of subjects making loss of form errors on each path and median severity of error for these subjects

\begin{tabular}{|c|c|c|c|c|}
\hline \multirow[t]{2}{*}{ Path } & \multicolumn{2}{|c|}{$\begin{array}{l}\text { Parkinson's disease } \\
(N=18)\end{array}$} & \multicolumn{2}{|c|}{$\begin{array}{l}\text { Control } \\
(N=14)\end{array}$} \\
\hline & No & $\begin{array}{l}\text { Median } \\
\text { severity }\end{array}$ & No & $\begin{array}{l}\text { Median } \\
\text { severity }\end{array}$ \\
\hline $\begin{array}{l}3 \\
5 \\
6 \\
7\end{array}$ & $\begin{array}{r}4 \\
4 \\
10 \\
15\end{array}$ & $\begin{array}{l}2 \\
1 \\
2 \\
4\end{array}$ & $\begin{array}{l}0 \\
0 \\
2 \\
7\end{array}$ & $\begin{array}{l}- \\
* \\
*\end{array}$ \\
\hline
\end{tabular}

* See text for explanation of missing values.
Path 7 improved after redemonstration. In some cases several redemonstrations were added with no improvement noted. Loss-of-form errors in the Parkinson's disease group did not correlate with any facet of the symptom severity rating. Only two control subjects made loss-of-form errors prior to Path 7 (one slight and one severe error on Path 6). On Path 7, seven of the control subjects did not initially reproduce the missing segment. Ratings for the controls' performance are not included in table 2 because, rather than making errors, controls often refused to attempt performance prior to redemonstration of Path 4 . While this would be rated as maximal error in our rating system, it would not be truly descriptive of the controls' performance. Six of the seven controls were aware of their inability to complete the missing segment; redemonstration of Path 4 led to improvement in performance of five of the control subjects.

Tracing errors. In the Parkinson's disease group, ten subjects made tracing errors on at least one design and five made severe errors (table 3 ). It was not possible to relate tracing error ratings to specific signs of Parkinson's disease. Tracing error was also not related to the complexity of the paths, occurring with comparable frequency in each. No correlation was found with any cognitive measure. In the control group, tracing errors were infrequent and of slight severity (table 3). For Path 7, control's tracing error ratings are taken from the first attempt they made at tracing the path. In some cases, this occurred after redemonstration of Path 4.

Hesitation errors. In the Parkinson's disease group, hesitation errors occurred in the tracing of all paths (table 4), but were not related to severity of Parkinson's disease, the complexity of the paths, or to any of the cognitive measures. In the control group, hesitation errors occurred only in degraded paths (table 4). These were typically pauses during which the subject attempted to determine the

Table 3 Tracing errors: number of subjects making tracing errors on each path and median error severity for those subjects

\begin{tabular}{|c|c|c|c|c|}
\hline \multirow[t]{2}{*}{ Path } & \multicolumn{2}{|c|}{$\begin{array}{l}\text { Parkinson's disease } \\
(N=18)\end{array}$} & \multicolumn{2}{|c|}{$\begin{array}{l}\text { Control } \\
(N=14)\end{array}$} \\
\hline & No & $\begin{array}{l}\text { Median } \\
\text { severity }\end{array}$ & $N o$ & $\begin{array}{l}\text { Median } \\
\text { severity }\end{array}$ \\
\hline $\begin{array}{l}1 \\
2 \\
4 \\
5 \\
6 \\
7\end{array}$ & $\begin{array}{l}6 \\
4 \\
5 \\
6 \\
3 \\
4\end{array}$ & $\begin{array}{l}1 \\
2 \\
3 \\
2 \\
4 \\
3\end{array}$ & $\begin{array}{l}0 \\
2 \\
0 \\
0 \\
0 \\
1\end{array}$ & $\begin{array}{l}\overline{1 \cdot 5} \\
\overline{-} \\
\overline{1}\end{array}$ \\
\hline
\end{tabular}


Table 4 Hesitation errors. Number of subjects making hesitation errors on each form and median error for these subjects

\begin{tabular}{|c|c|c|c|c|c|c|c|c|}
\hline \multirow[t]{3}{*}{ Form } & \multicolumn{4}{|c|}{ Endpoint hesitation } & \multicolumn{4}{|c|}{ Tracking hesitation } \\
\hline & \multicolumn{2}{|c|}{ Parkinson's disease } & \multicolumn{2}{|c|}{ Control } & \multicolumn{2}{|c|}{ Parkinson's disease } & \multicolumn{2}{|c|}{ Control } \\
\hline & No & $\begin{array}{l}\text { Median } \\
\text { severity }\end{array}$ & No & $\begin{array}{l}\text { Median } \\
\text { severity }\end{array}$ & No. & $\begin{array}{l}\text { Median } \\
\text { severity }\end{array}$ & No & $\begin{array}{l}\text { Median } \\
\text { severity }\end{array}$ \\
\hline $\begin{array}{l}1 \\
2 \\
3 \\
4 \\
5 \\
6 \\
7\end{array}$ & $\begin{array}{l}4 \\
3 \\
3 \\
2 \\
5 \\
3 \\
2\end{array}$ & $\begin{array}{l}4 \\
2 \\
2 \\
1 \\
1 \\
1 \\
4\end{array}$ & $\begin{array}{l}0 \\
0 \\
0 \\
0 \\
0 \\
1 \\
3\end{array}$ & $\begin{array}{l}\bar{Z} \\
\overline{-} \\
\overline{4} \\
1\end{array}$ & $\begin{array}{l}4 \\
5 \\
4 \\
3 \\
5 \\
9 \\
8\end{array}$ & $\begin{array}{l}1 \\
2 \\
2 \\
1 \\
2 \\
3 \\
2\end{array}$ & $\begin{array}{l}0 \\
0 \\
0 \\
1 \\
0 \\
5 \\
5\end{array}$ & $\frac{-}{\overline{-}}$ \\
\hline
\end{tabular}

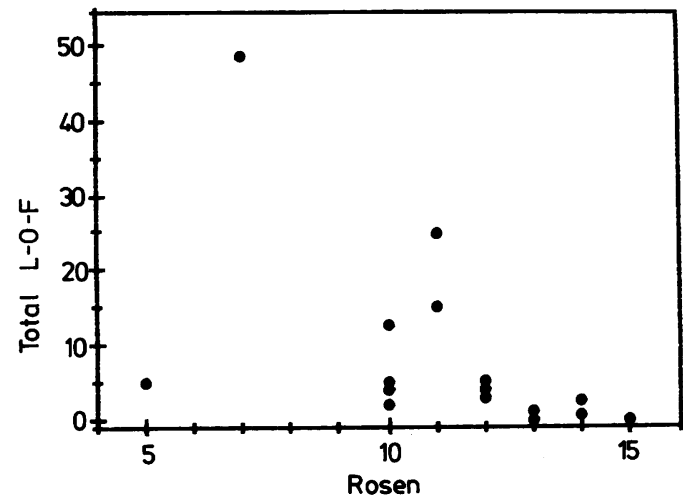

Fig 3 Scatter of correlation between Parkinson's disease patients' scores on Rosen Drawing Test and total loss-ofform errors.

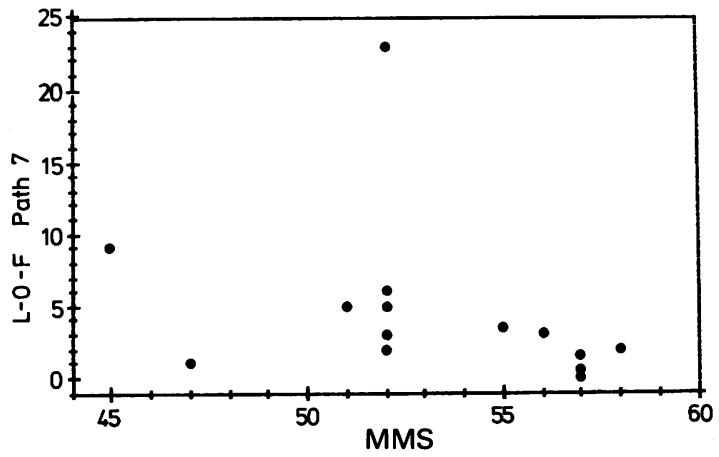

Fig 4 Scatter of correlation between Parkinson's disease patients' scores on the modified Mini-Mental State examination and loss-of-form errors on Path 7.

continuation of the pattern into the degraded portion. Again, ratings for Path 7 in the controls are based on the first performance attempt.

Relation of errors to cognitive tasks. In the Parkinson's disease group, the sum of loss-of-form error ratings on all paths correlated with performance on the Rosen Drawing Test $(r=0 \cdot 50, p=0 \cdot 048)($ fig 3$)$. The sum of loss-of-form errors did not correlate significantly with the modified MMS scores, but total loss-of-form errors on Paths 3,6 and 7 did $(r=-0 \cdot 84$, -0.63 , and -0.51 respectively; $p=0.05$ ) (fig 4 ). Tracing and hesitation errors did not correlate with modified MMS, Rosen Drawing Test, or loss-of-form errors.

Correlation of loss-of-form errors with neuropsychological variables was not possible in the control group because of the lack of variance in the error ratings (that is error ratings were either at the minimum or maximum). $T$ tests comparing controls $\varrho$ who were successful and not successful on Path 7 of the tracing task revealed no differences between 8 these groups in modified MMS or Rosen Drawing Test scores.

\section{Discussion}

The generation of tracing and hesitation errors by the Parkinson's disease group, and the paucity of these errors in the controls, suggests that the abnormalities may be specifically related to Parkinson's disease. These errors could be related to the motor symptoms of Parkinson's disease, although we found no correlation of errors with any specific rating of Parkinson's disease. Correlations between visual tracking performance and bradykinesia have been described by others but were not found in this study. ${ }^{11}$ Mortimer $e t$ $a l^{12}$ used a random tracking test to measure bradykinesia; their findings related this measure to impaired performance on tests of visual-spatial reasoning. Others have also described a relationship between bradykinesia and visuospatial performance. ${ }^{5}{ }^{13}$

Loss-of-form (errors in filling in missing segments), occurred in both Parkinsonian patients and controls, but performance in the two groups was quantitatively and qualitatively different. First, in the Parkinson's disease group, these errors occurred on 
all degraded paths and increased in frequency and severity as the complexity of the paths increased. Controls made fewer errors and only on the more complex designs. Second, controls tended to make errors of omission; most would not trace the missing segment until redemonstration. Patients made errors of commission, generating inaccurate movements without apparent insight. Third, the controls, unlike the patients, eliminated their errors with additional practice. Finally, loss-of-form errors correlated with performance on the construction and general intellectual tasks only in the Parkinson's disease group.

Although control's errors were minor, they nonetheless occurred on what appears to be a relatively simple task. It is possible that their greater age and lower level of education played a role in their performance on the tracing and constructional tasks. Age and level of education have both been found to correlate with performance on intellectual tasks in Parkinsonians as well as controls. ${ }^{5}$ Despite this relationship, patients still performed more poorly on the tracing task than controls.

The relation between patients' loss-of-form errors and performance on the constructional task suggests that these tasks are mediated by a similar process. Poor performance on similar tasks has been encountered frequently in Parkinson's disease and have been variously described with such terms as visuomotor ${ }^{14}$ sensorimotor ${ }^{15}$ and motor planning deficits. ${ }^{13}{ }^{16}$ It is possible that these terms are all attempts to characterise a perceptual motor deficit which is not related to the specific motor problems in Parkinson's disease such as tremor or rigidity. This deficit could represent an inability to coordinate perception with certain motor functions in order to generate movements based on an internal concept of space (or a motor plan). Perception refers to the ability to discriminate external sensory information, in this case visual. The motor functions consist of a series of movements which are sequentially performed. The coordination of these two activities in order to fulfil a motor plan may represent a higher order of motor control.

The tracing task in this study required both sequential and predictive movements. Specific movements had to be accomplished in the absence of visual feedback, forcing the subject to generate predictive movements based on an internal spatial percept. Flowers and others have also demonstrated this deficit in the generation of movement in the absence of visual guidance in both Parkinson's disease and non-human primates with lesions in the basal ganglia..$^{6}{ }^{14}{ }^{17-19}$ The tracing task also demands that the movements be generated in their proper sequence, beginning and terminating at their proper time. Deficits in the sequencing of movement have often been demonstrated in Parkinson's disease. ${ }^{15} 2021$

In the constructional task, the subjects again were required to generate sequences of movements that satisfied set spatial demands. In this case visual guidance was present in the form of the designs, but the designs were often complex enough to challenge the subject's ability to organise the movements necessary to reproduce them. Other investigators have demonstrated constructional deficits in Parkinson's disease which may also reflect this inability to organise or sequence the movements necessary for successful performance..$^{13} 22$ Other tracking studies demonstrate that even when patients are informed that a target is moving in a specific sequence they cannot use this information to improve their tracking accuracy. ${ }^{6}{ }^{16}$

According to Marsden ${ }^{16}$ the basal ganglia may be responsible for the automatic execution of learned motor plans; that is, they take part in sequencing the motor programs needed to accomplish a motor plan. The mechanism through which the basal ganglia may aid in this activity is unknown.

Angel' $\mathrm{s}^{23}$ hypothetical efference copy system may explain how perceptual motor coordination takes place. In a tracking study, he induced subjects to make incorrect movements. Subjects could correct these movements even when there was no external feedback to inform them that they were incorrect. $\mathrm{He}$ suggested that subjects corrected errors using efference copy, which he defined as a central representation of efferent motor activity. These representations of motor commands are evaluated for their appropriateness or effectiveness. Incorrect or ineffective movements are corrected either before or as they occur, with or without external feedback. Angel observed this error correction mechanism in Parkinson's disease but it was slowed, suggesting that the basal ganglia were involved in an efference copy system. ${ }^{24}{ }^{25}$ Furthermore, this may imply that the basal ganglia aid in the monitoring of ongoing movement and may even determine when to move from one portion of a motor plan to the next.

In single unit studies of basal ganglia areas in primates, the animals also made tracking movements which were disrupted and then had to be corrected. Cells fired more frequently after the corrective movements had been initiated, suggesting that the basal ganglia are involved in monitoring as opposed to initiating the movements. ${ }^{25-28}$ Prism adaptation, another task which requires the coordination of attempted movements with an internal percept, is disrupted with lesions to the basal ganglia in primates and man. Again this suggests that the basal ganglia are critical in perceptual motor coordination. ${ }^{29-31}$ Similar monitoring systems involving the basal 
ganglia have been suggested by others ${ }^{32}{ }^{33}$ and are anatomically feasible. ${ }^{34}$

The deficit in the coordination of perceptual and motor activity could be viewed as purely motor in nature. ${ }^{16}$ On the other hand, this process may have an intellectual component for the following reasons: (1) Loss-of-form errors in this study correlated with performance on the mental status examination, (2) Investigators have reported deficits in purely intellectual tasks which require Parkinsonian subjects to monitor test responses and use this information to modify later performance. (An example of this is the Wisconsin card sort) ${ }^{35}$ (3) Poor performance on construction tasks, block design and puzzle assembly tasks have been observed in Parkinson's disease ${ }^{12}{ }^{13} 22$ as well as lower scores on the Performance subtests of the Wechsler Adult Intelligence Scale ${ }^{4}$ all of which are measures of intellectual ability, (4) Spatial representation, which is dependent on perceptual motor coordination, ${ }^{36}$ is also defective in Parkinson's disease; for example, patients perform poorly on the Aubert task, a test of horizontal orientation. ${ }^{37}$ Potegal has also demonstrated that the basal ganglia may be necessary for locating objects in space relative to the observer. ${ }^{31}$

Our data may suggest that perceptual motor impairment in Parkinson's disease is a form of intellectual impairment associated with higher-order motor control of sequential and predictive voluntary movements. This may reflect a disturbance in basal ganglia participation in a hypothetical efference copy system. It is a subtle deficit that appears in most Parkinsonian patients and does not appear to simply be related to motor symptoms of Parkinson's disease.

We thank the staff and members of the South East Queens Multi-Service Senior Citizens Center for their aid and participation in this study, and Drs Cote and Fahn for their assistance.

This work was supported by the Parkinson's Disease Foundation and the Epply Foundation (Mr Stern) and in part by a grant to Dr Mayeux (AG02802).

\section{References}

${ }^{1}$ Bowen FP, Hoehn MM, Yahr MD. Cerebral dominance in relation to tracking and tapping performance in patients with Parkinsonism. Neurology (Minneap) 1972;22:32-9.

${ }^{2}$ Bowen FP, Hoehn MM, Yahr MD. Parkinsonism: alterations in spatial orientation as determined by a route-walking test. Neuropsychologia 1972;10:335-61.

${ }^{3}$ Yahr MD, Procter-Bowen F. Intellectual deficits in parkinsonism. Int J Neurol 1975;10:280-6.
${ }^{4}$ Loranger AW, Goodell H, McDowell FH, Lee JE, Sweet RD. Intellectual impairment in Parkinson's syndrome. Brain 1972;95:405-12.

${ }^{5}$ Mayeux R, Stern Y, Rosen J, Leventhal J. Depression, intellectual impairment, and Parkinson disease. Neurology (NY) 1981;31:645-50.

${ }^{6}$ Flowers K. Lack of prediction in the motor behaviour of Parkinsonism. Brain 1978;101:35-52.

${ }^{7}$ Mayeux R, Stern Y, Rosen J. Visuospatial function in Parkinson disease. (Abstract.) Neurology (Minneap) 1980;30:392.

${ }^{8}$ American Psychiatric Association. Diagnostic and Statistical Manual of Mental Disorders. 3rd ed. Washington: APA, 1980.

${ }^{9}$ Folstein MF, Folstein SE, McHugh PR. "Mini-mental state" a practical method for grading the cognitive state of patients for the clinician. $J$ Psychiatr Res 1975;12:189-98.

${ }^{10}$ Rosen W. The Rosen Drawing Test. New York: Veterans Medical Center.

${ }^{11}$ Shibaski H, Tsuji S, Koroiwa Y. Occulomotor abnormalities in Parkinson's disease. Arch Neurol 1979;36:360-4.

12 Mortimer JA, Pirozzolo FJ, Hansch EC, Webster DD. Relationship of motor symptoms to intellectual deficits in Parkinson's disease. Neurology (NY) 1982;32:133-7.

${ }^{13}$ Joubert M, Barbeau A. Akinesia in Parkinson's disease. In: Barbeau A, Brunette JR, eds. Progress in Neurogenetics. Amsterdam: Exerpta Medica, 1969.

${ }^{14}$ Bowen FP. Visuomotor deficits produced by cryogoni lesions of the caudate. Neuropsychologia 1969;1:59 65.

${ }^{15}$ De L. Horne DJ. Sensorimotor control in parkinsonism. J Neurol Neurosurg Psychiatry 1973;36:742-6.

${ }^{16}$ Marsden CD. The mysterious motor function of the basal ganglia: The Robert Wartenberg Lecture. Neurology (NY) 1982;32:514-39.

${ }^{17}$ Cooke JD, Brown JD, Brooks VB. Increased dependence on visual information for movement control in patients with Parkinson's disease. Can J Neurol Sci 1978;5:41315.

${ }^{18}$ Hore J, Meyer-Lohmann J, Brooks VB. Basal ganglia cooling disables learned arm movements of monkeys in the absence of visual guidance. Science 1977;195:584 6.

${ }^{19}$ Caan W, Stein JF. The effects of cooling globus pallidus on manual tracking in trained rhesus monkeys. $J$ Physiol (Lond) 1979;293:69P

${ }^{20}$ Schwab RS, Chafetz ME, Walker S. Control of two simultaneous voluntary motor acts in normals and in parkinsonism. Arch Neurol Psychiat 1954;75:591-8.

${ }^{21}$ Perret E. Simple motor performance of patients with Parkinson's disease before and after a surgical lesion in the thalamus. J Neurol Neurosurg Psychiatry 1968;31:284-90.

22 Botez MI, Barbeau A. Neuropsychological findings in Parkinson's disease. A comparison between various tests during long-term Leudopa therapy. Int J Neurol 1975;10:222-32.

${ }^{23}$ Angel RW. Efference copy in the control of movement. Neurology (Minneap) 1976;26:1164-8.

${ }^{24}$ Angel RW, Alston W, Higgins JR. Control of movement 
in Parkinson's disease. Brain 1970;93:1-14.

${ }^{25}$ Angel RW, Alston W, Garland H. L-Dopa and error correction time in Parkinson's disease. Neurology (Minneap) 1971;21:1255-60.

${ }^{26}$ Anderson RJ, Aldridge JW, Murphy JT. Function of caudate neurons during limb movements in awake primates. Brain Res 1979;173:489-501.

${ }^{27}$ Aldridge JW, Anderson RJ, Murphy JT. The role of the basal ganglia in controlling a movement initiated by a visually presented cue. Brain Res 1980;192:3-16.

${ }^{28}$ Dolbakyan E, Hernandez-Mesa N, Bures J. Skilled forelimb movements and unit activity in motor cortex and caudate nucleus in rats. Neuroscience 1977;2:73-8.

${ }^{29}$ Bossom J. The effect of brain lesions on prism-adaptation in monkey. Psychonemetric Science 1965;2:45-6.

${ }^{30}$ Bossum J, Ommaya AK. Visuo-motor adaptation (to prismatic transformation of the retinal image) in monkeys with bilateral dorsal rhizotomy. Brain 1968;91:161-72.
${ }^{31}$ Potegal M. The caudate nucleus egocentric localization system. Acta Neurobiol Exp 1972;32:479-94.

${ }^{32}$ Teuber H-L. Unity and diversity of frontal lobe functions. Acta Neurobiologica Experimentalis 1972;32:615-65.

${ }^{33}$ Teuber H-L. Complex functions of the basal ganglia. In: Yahr MD, ed. The Basal Ganglia. New York: Raven Press, 1976:151-68.

${ }^{34}$ Webster KE. Structure and function of the basal ganglia. A non-clinical view. Proc R Soc Med 1975;68:203-10.

${ }^{35}$ Bowen FP. Behavioral alterations in patients with basal ganglia lesions. In: Yahr MD, ed. The Basal Ganglia. New York: Raven Press, 1976:169-80.

${ }^{36}$ Held R, Freedman ST. Plasticity in human sensorimotor control. Science 1963;142:455-61.

${ }^{37}$ Teuber H-L, Procter F. Some effects of basal ganglia lesions in subhuman primates and man. Neuropsychologia 1964;2:85-93. 